\title{
An ingenious invasive weed optimization (IWO) aided maximum power tracking for partially shaded photovoltaic array
}

\author{
Sridhar R, Boopathi C S, Deepanjali Das, Sakshi Agrawal, Hardik Choubisa \\ Department of EEE SRM Institute of science and Technology, India
}

\begin{tabular}{l}
\hline \hline Article Info \\
\hline Article history: \\
Received Sep 20, 2018 \\
Revised Nov 17, 2018 \\
Accepted Mar 11, 2019
\end{tabular}

Keywords:

Invasive weed optimization Maximum power point tracking Partial shading

Particle swarm optimization

Perturb and observe

\begin{abstract}
The inborn non-direct power voltage trademark bends concerning barometrical temperature and light makes the photovoltaic (PV) source a discontinuous one. Maximum power point (MPPT) following is a procedure through which most extreme accessible power is yielded from the PV for the given purpose of time. Prior, the customary MPPT methods, for example, perturb and observe, incremental conductance, hill climbing and so forth strategies were utilized and these methods stayed inadequate when the PV source is partially shaded (PS), since amid (PS) the power voltage (P-V) bends show different power crests. There wins each possibility that the ordinary calculations will stall out to the local maximum point and the global maximum point won't be accomplished and in this way control misfortune is brought about. The metaheuristic calculations give better arrangements however confront the downside of high weight on processor and enormous number of information prerequisites. In this way, in this paper, a novel calculation in light of invasive weed optimisation (IWO) technique is utilized to locate the Global maximum point for MPPT under in part shaded condition and it is contrasted and its nearby partner differential evolution(DE) MPPT algorithm and furthermore with the very much settled in perturb and observe $(\mathrm{P} \& \mathrm{O})$ calculation. The proposed calculation is actualized in MATLAB condition and tried on a 3-board PV cluster arrangement of $150 \mathrm{~W}$. The flexibility of the calculation is tried through various experiments and the outcomes demonstrate the effectiveness and exactness of the proposed calculation in finding the global maximum point.
\end{abstract}

Copyright $\odot 2019$ Institute of Advanced Engineering and Science. All rights reserved.

\section{Corresponding Author:}

Sridhar R,

Department of EEE SRM Institute of science and Technology,

Chennai, India.

Email: sridharmanly@gmail.com

\section{INTRODUCTION}

In this period where the world is confronting contamination and vitality emergency on a huge scale there is a desire to move to the sustainable power sources. In this deprecatory condition the world has now comprehended the noticeable quality of the sustainable power source assets [1]. Out of a wide range of these sources sunlight based and wind vitality have given the best ideal outcomes on a huge scale. The new creating advancements, top of the line gadgets, new topologies, most up to date innovations, vitality administration frameworks are adding to the enhanced execution of sunlight based photovoltaic (PV), wind and other inexhaustible sources [2]. Solar powered photovoltaic vitality speaks to spotless and green wellspring of vitality decreases carbon emissions apparently. Every country have down to earth focus of introducing $50 \mathrm{GW}$ PV frameworks on a normal premise every year. Actually, the significant obstacle that any PV source inalienably has is its nonlinear yield trademark bends concerning climatic temperature and 
light [3]. Maximum power point tracking (MPPT) is an irreplaceable procedure should be introduced in any PV framework to make the PV to work at its pinnacle control in the nonlinear bends. The writing study on MPPT proposes that different conventional techniques have been utilized to recognize maximum power point in a PV board.

\subsection{Background}

Perturb and Observe $(\mathrm{P} \& \mathrm{O})[4]$ technique is a standout amongst the most widely recognized customary strategy utilized because of its simplicity of execution yet does not indicate extraordinary preferred standpoint in regard of number of emphases, non-direct conditions and power misfortune [5]. Here the working point over the PV control bend is iteratively moved to look for the pinnacle control and the power yields will dependably have an oscillatory nature because of the nonstop bother. Then again, the Incremental conductance (INC) [6] technique is equipped in taking care of the yield motions however the execution and equipment acknowledgment is a dull one. Various MPPT strategies have been proposed in inquire about discussion yet these procedures have its own particular legitimacy and negative marks [7]. Accordingly, in dominating cases $\mathrm{P} \& \mathrm{O}$ is favoured over its partner for its straightforward and simple usage, and furthermore by choosing the irritation rate judiciously the oscillatory nature is reduced generously.

In conditions when the sun irradiance is falling homogenously on all the modules, the power-voltage (P-V) curve will have a solitary pinnacle for the given time, but at the same time when the sun based irradiance isn't uniform on all modules then the P-V curves of PV demonstrates multiple power peaks and this condition is realized as partially shaded state [8]. Continuously circumstance, this non consistency of sun oriented irradiance on couple of modules emerges because of tall structures, trees, shadow of mists and so on. Because of the numerous power tops, P\&O MPPT faces a tough assignment in distinguishing the global maximum power point (GMPP) among the other local maximum power point (LMPP) and gets stagnated at first pinnacle be it GMPP or LMPP [9] and furthermore can't separate amongst LMPP and GMPP. Another exploration worldview of proposing MPPT for somewhat shaded PV cluster dragged much consideration. The regular MPPT strategies either subjected to adjustments in seeking plan or nestled with keen systems like fuzzy and simulated neural system [10-11]. Be that as it may, these methods acted capacity weights and like well as for unexpectedly changing barometrical conditions it remained a daft wander [12].

Hence the analysts tend towards the more capable calculations which has natural cautiousness over the entire hunt zone. The most famous metaheuristic calculation is Particle Swarm Optimization roused by the social conduct of winged animal rushing, utilizes various particles which explore around the search space to locate the optimum point (i.e. the ideal position) [13]. PSO MPPT has been a disclosure for MPPT analysts as it effortlessly finished over other regular counterparts [14]. The hunt execution and union of PSO MPPT has been enhanced further when analysts adjusted the traditional PSO into adaptive perceptive (APPSO) [15] and, through improved search algorithms [16-18]. Differential evolution (DE) with PSO (DEPSO) [19] has a blend of differential evolution and PSO. Here, execution and seeking capacity got upgraded however the execution process is hectic. Another well known swarm-based calculation is Ant Colony Optimization, first proposed by Dorigo [20], is enlivened by the social conduct of ants in an insect settlement. Truth be told, the social knowledge of ants in finding the nearest way from the home and a wellspring of nourishment is the fundamental motivation of this calculation. The mission of new calculation and the analysts enthusiasm towards worldwide inquiry calculation driven procedures are obvious through MPPT calculations like are differential evolution (DE) algorithms, dolphin Partner Optimization (DPO), bat-enlivened calculation (BA), firefly calculation (FA), Hunting Search (HS), bird mating optimizer (BMO) [21-26]. The seeking capacity upgrade and less computational weight are the requesting factors for any new MPPT. Mirjalil built up a dark wolf advancement (GWO) calculation and whale optimization (WO) imitated from their separate chasing conduct [27-28].

\subsection{Problem}

The itemized writing overview expressly infers the significance of presenting new worldwide hunt calculation and tests its validity over the other similarly intense partners. Invasive weed optimization (IWO) calculation presented by Mehrabian and Lucas in 2006 [29] known for its less parameter taking care of search checks and incredible robustness. IWO has rendered its hand to take care of different building issues like economic load dispatch [30], orientation and designing of antennas [31], and nonstop enhancement issues, for example, non-linear [32] and discrete issues, for example, multi-objective adaptable issues [33]. According to author's learning, it is deduced from the broadwriting overview that there is no evidence of utilizing this strong meta-heuristic IWO calculation for MPPT. Subsequently, in this paper IWO (Invasive Weed Optimization) calculation is proposed to discover the MPPT under partially shaded condition. 


\section{PV MODELLING AND CHARACTERISTIC CURVES DURING UNIFORM AND PARTIAL SHADING CONDITIONS \\ 2.1. PV Modelling}

Modelling the PV with mathematical equations is very vital to realize the PV panel with customized rating and also to do analysis during varying atmospheric conditions. The PV cell or a panel can be equivalently represented by the in Figure 1, where the photo current source $\mathrm{I}_{\mathrm{ph}}$ is denoted parallel to a two diode network; hence this model is called as two diode model. The choice of two diode model is advantageous than single diode model as this structure is very responsive for even subtle changes in irradiation and temperature.

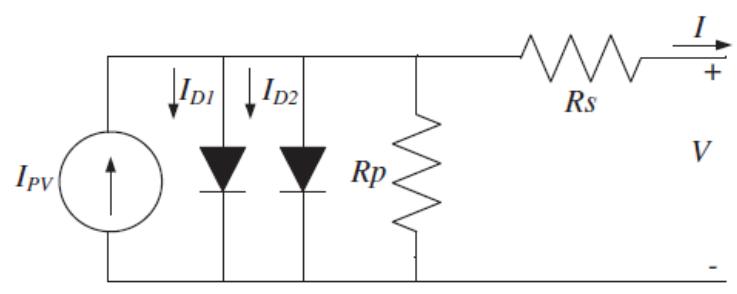

Figure 1. Two diode model of PV cell

The current leading out from the circuit is

$$
I=I_{P V}-I_{o 1}\left[\exp \left(\frac{V+I R_{s}}{a_{1} V_{T 1}}\right)-1\right]-I_{o 2}\left[\exp \left(\frac{V+I R_{s}}{a_{2} V_{T 2}}\right)-1\right]-\left(\frac{V+I R_{s}}{R_{p}}\right)
$$

PV current inherently relies on temperature and irradiation, and the relation is given as

$$
I_{P V}=\left(I_{P V_{-} S T C}+K_{i} \Delta T\right) \frac{G}{G_{S T C}}
$$

The reverse saturation current expression of a diode, $I_{o}$ is

$$
I_{o}=\frac{\left(I_{P V_{-} S T C}+K_{i} \Delta T\right)}{\exp \left[\left(V_{o c, S T C}+K_{v} \Delta T\right) / a V_{T}\right]-1}
$$

Since the saturation currents of two diodes are equal,

$$
I_{o 1}=I_{o 2}=I=\frac{\left(I_{P V_{-} S T C}+K_{i} \Delta T\right)}{\exp \left[\left(V_{o c, S T C}+K_{v} \Delta T\right) /\left\{\left(a_{1}+a_{2}\right) / p\right\} V_{T}\right]-1}
$$

The current -voltage and power -voltage curves of a typical $100 \mathrm{~W}$ PV panel is shown in Figure 2.

\subsection{Characteristic Curves Of PV Array under Uniform and Partial Shading}

The PV board faces a non consistency in the disconnection zones on it because of the shadows caused by trees, mists or tall structures. In this situation, a few modules are under mostly shaded and some get immediate irradiance. The undeniable result is that the incompletely shaded modules produce similarly less measure of current. Here if the PV cluster modules are set in arrangement, so the current through the parallel protection of incompletely shaded modules, ushers to a voltage drop. This unenviable voltage drop diminishes the most extreme yield control and makes hotspots. This issue can be settled just by a sidestep diode i.e bypassing streams of all modules through it. Then again, if parallely associated then the shaded string pulls back current from rest of the parallel associated strings. This flowing current lessens the proficiency of the PV board and makes it unpalatable. This said issue by and large reduced to a degree by 
interfacing by pass diodes in parallel to the PV boards however it brings about PV yield P-V bends having different power crests which confuses the work of MPPT controller.

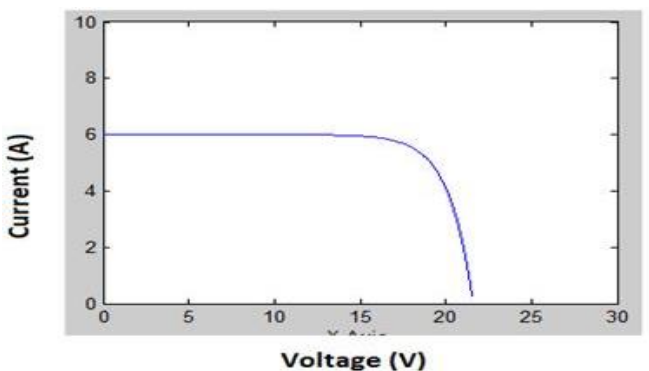

(a) I-V curve

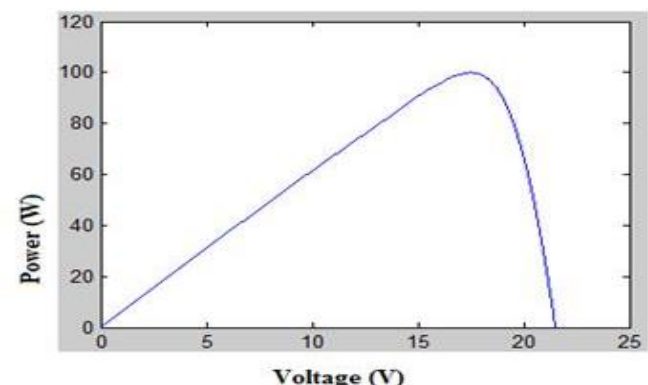

(b) P-V curve

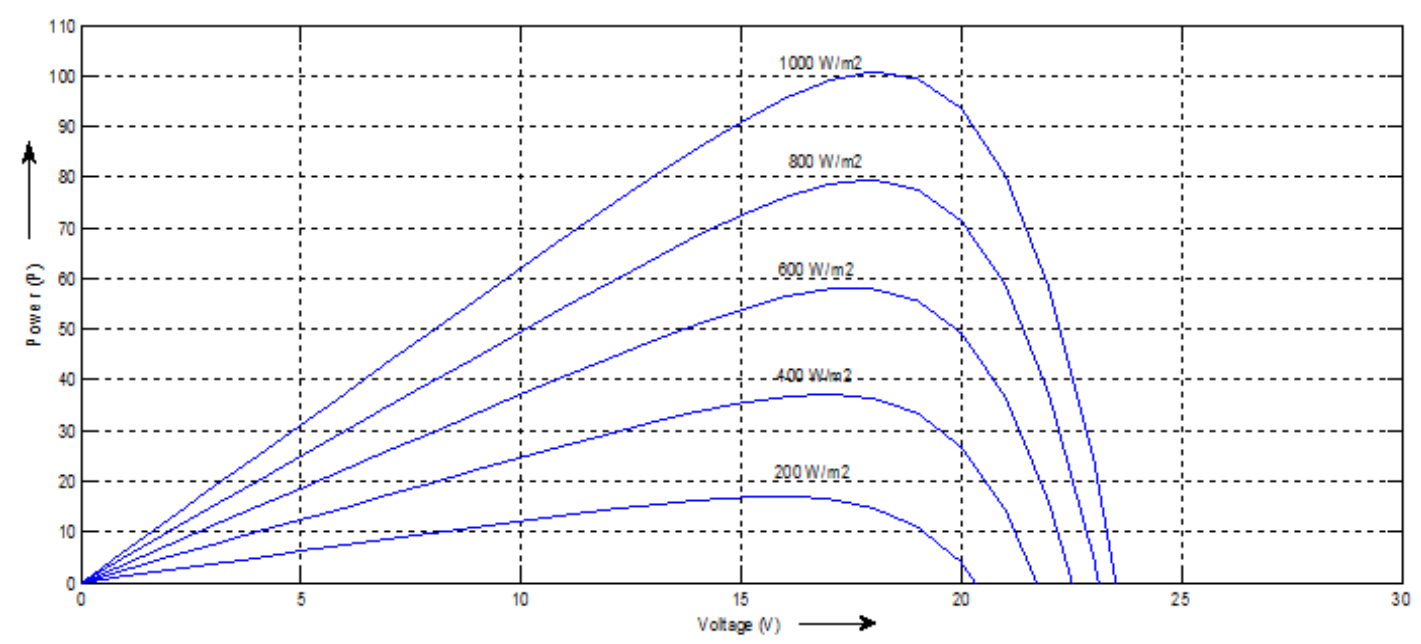

(c) P-V curves for varying irradiation

Figure 2. Characteristics curves of $100 \mathrm{~W}$ panel

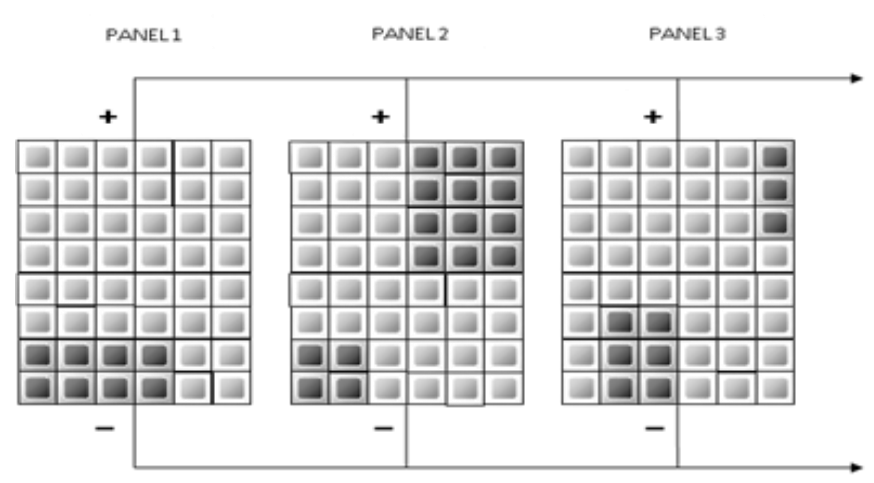

Figure 3. Partially shaded PV array

Table 1 provides the information of the various PV panel specification also we have taken three panels under uniform and non-uniform shading conditions. Figure 3 shows the arrangement. As we can see that for different values of temperature and irradiation, we get multiple peaks in the Figure 4(b). We get two LMPP at $30 \mathrm{~W}$ and $45 \mathrm{~W}$ and one GMPP at 52W. Whereas, under uniform shaded condition we got cumulative peak at 150W in Figure 4(a). Table 2 and Table 3 below illustrate the values of power and voltage of all the three panels under both conditions. 
Table 1. Pv Panel Specifications

BPU Polycrystalline 50 Watt

Maximum Power $\left(\mathrm{P}_{\mathrm{mp}}\right) \quad 50 \mathrm{~W}$

Short circuit current (Isc) $\quad 15 \mathrm{~V}$

Open circuit Voltage (Voc) $\quad 4.2 \mathrm{~A}$

Voltage at Pmp (Vmp)) 14.4

Cuttent at Pmp (Imp) 4.0 A

Table 2. Non Shaded Pv Array Condition

\begin{tabular}{ccccc}
\hline Panel & $\mathrm{T}^{\circ} \mathrm{C}$ & $\mathrm{G}\left(\mathrm{W} / \mathrm{m}^{2)}\right.$ & $\mathrm{P}(\mathrm{W})$ & $\mathrm{V}_{\mathrm{mp}}$ \\
\hline PV 1 & 20 & 1.2 & 50 & 16 \\
PV 2 & 20 & 1.2 & 50 & 16 \\
PV 3 & 20 & 1.2 & 50 & 16 \\
\hline
\end{tabular}

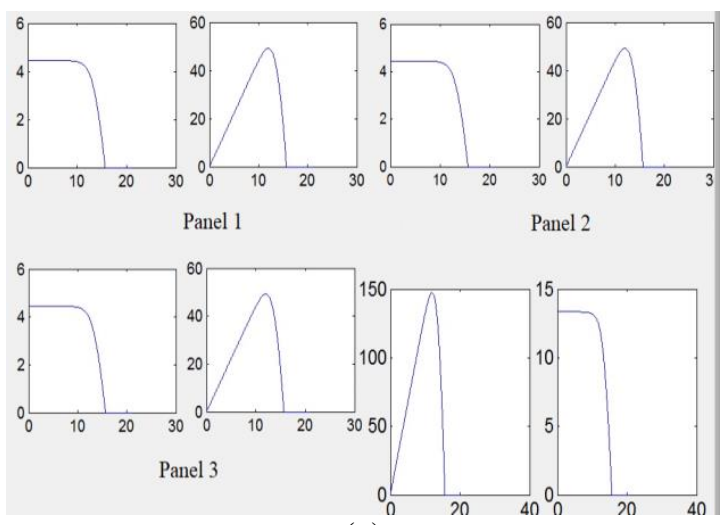

(a)
Table 3. Shaded Pv Array

\begin{tabular}{ccccc}
\hline Panels & $\mathrm{T}^{\circ} \mathrm{C}$ & $\mathrm{G}\left(\mathrm{w} / \mathrm{m}^{2)}\right.$ & $\mathrm{P}(\mathrm{W})$ & $\mathrm{V}_{\mathrm{mp}}(\mathrm{V})$ \\
\hline PV 1 & 11.8 & 727 & 29 & 16 \\
PV 2 & 41.25 & 492 & 20 & 14 \\
PV 3 & 68.02 & 37 & 15 & 10.5 \\
\hline
\end{tabular}
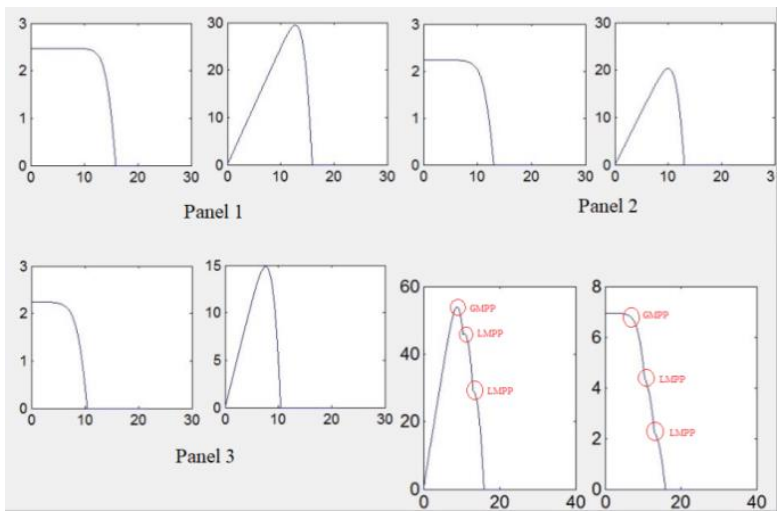

(b)

Figure 4. Cumulative characteristic curves of PV array. (a) uniform irradiation for all three panels, (b) non uniform irradiation for all three panels.

\section{INVASIVE WEED OPTIMIZATION MPPT ALGORITHM}

In Invasive Weed Optimization (IWO), the weeds are utilized to acquire the proposed ideal arrangement, which are spread everywhere throughout the hunt region and the aggregate number of the considerable number of weeds speak to the number of inhabitants in the territory. The wellness of each weed to check whether it is close or a long way from the ideal arrangement is found and number of seeds is delivered around each weed where weeds with low wellness esteem create less seeds than weeds with abnormal state wellness esteem. The obtained seeds are ordinarily appropriated around the parent weed whose mean is equivalent to zero with various estimation of difference and standard deviation. The populace is then overhauled to incorporate every one of the weeds and produced seeds. These procedures are rehashed and again until the point when the greatest number of all weeds and seeds are gotten barring weeds with bring down level wellness esteem in without fail. This procedure is ceased when the most extreme number of emphases are come to or when the weed with the best arrangement is relatively close to the ideal arrangement. The IWO search contains four critical stages say initialization of populace, reproduction, scattering and avoidance as delineated in Figure 5-6.
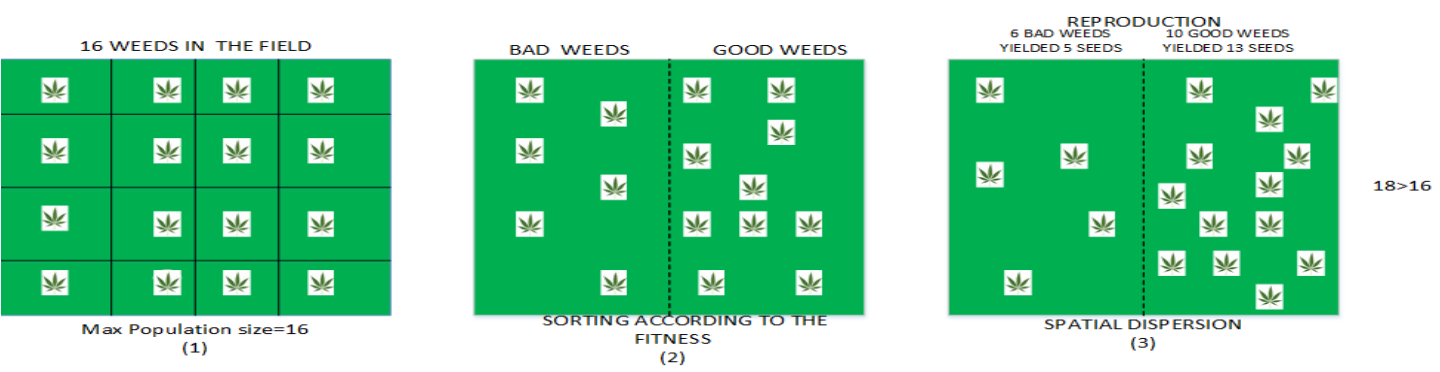

Figure 5. Succession of IWO 


\subsection{Initialize a populace}

At to start with, weeds (initials arrangements) are created arbitrarily and spread everywhere throughout the D-dimensional hunt space. The best and most exceedingly awful wellness esteems are gotten by ascertaining the wellness of each weed.

\subsection{Reproduction}

Figure the quantity of seeds delivered by each weed to its wellness. The higher the wellness, the an ever increasing number of seeds are delivered, where the quantity of created seeds by each weed is dictated by the given direct equation;

$$
\text { Weed }_{\mathrm{n}}=\left(S_{\max }-S_{\min }\right) \frac{f \cdot f \text { (worst })}{f(\text { best }) \cdot f(\text { worst })}+S_{\min }
$$

Where, $f$ is the considered wellness of the weed, fbest and fworst are the best and most exceedingly terrible wellness in the present populace individually, Smax and Smin are the greatest and least seeds numbers separately.

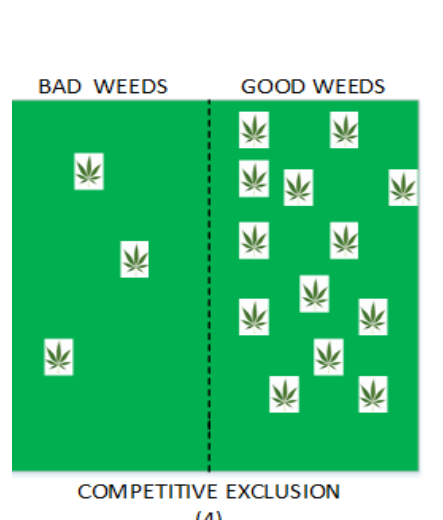

(4)

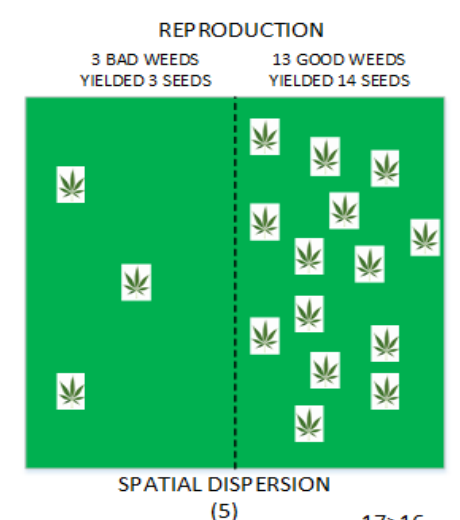

(5)

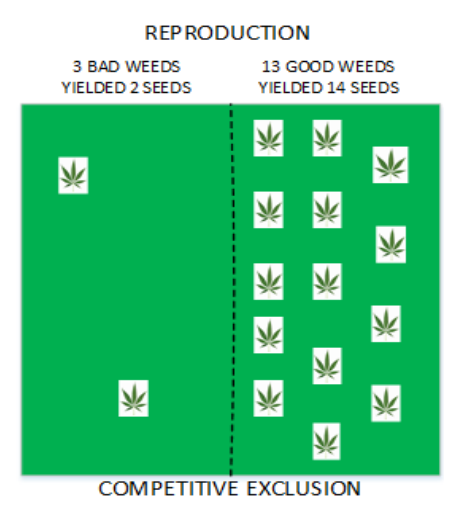

(6)
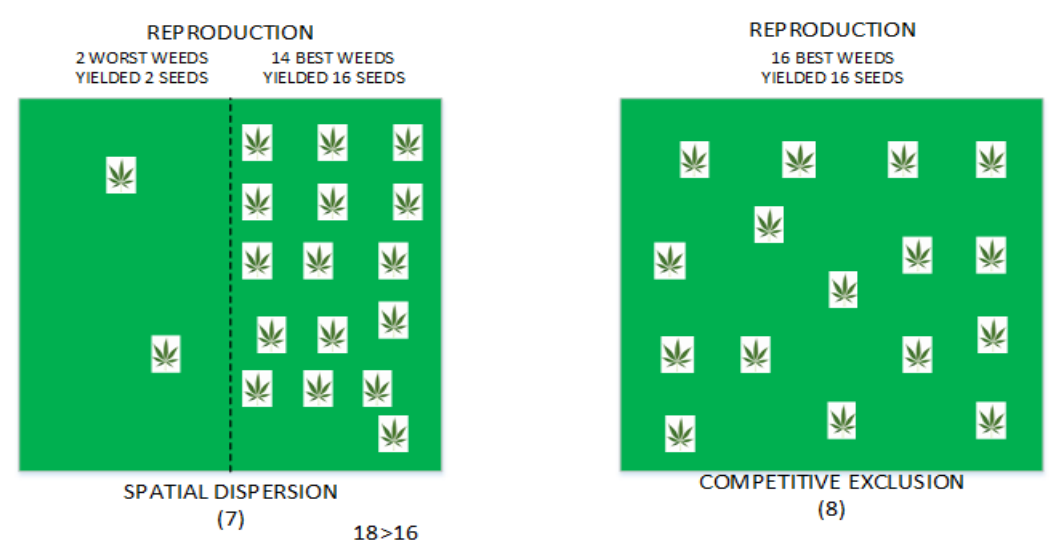

(8)

Figure 6. Succession of best weed pervasiveness

\subsection{Spatial scattering}

Each parent weed delivers various seeds which are spread typically around the weed with a mean equivalent to zero and fluctuating estimations of standard deviation. This is to affirm that they stick around their parent weed. As per the given direct condition, standard deviation $\sigma$ diminishes steadily from introductory incentive to a last an incentive in each cycle of the calculation;

$$
\sigma_{\text {cur }=}=\frac{(\text { iter }(\max )-\text { iter })^{n}}{i t e r(\max )^{\wedge} n}(\sigma(\text { int })-\sigma(\text { final }))+\sigma(\text { final })
$$

Where; 
iter $_{\max }$ is the most extreme number of cycles, $\sigma_{\text {cur }}$ is the present emphasis standard deviation, $\sigma$ init is the underlying standard deviation, $\sigma_{\text {final }}$ speaks to definite standard deviation and $\mathrm{n}$ speaks to balance record.

\subsection{Competitive prohibition}

After numerous cycles, because of quick multiplication, the quantity of seeds and weeds in a state will surpass a most extreme populace measure. Thus, in request to wipe out the most exceedingly bad arrangements, the seeds and their parent weeds are orchestrated together from the best fitted to the slightest fitted to keep the quantity of weeds and seeds inside the greatest populace measure.

\section{IWO MPPT FOR PARTIALLY SHADED PV ARRAY}

IWO MPPT controller is implemented either having duty cycle as a searching operator or the operating voltage as control parameter. In this work, the operating voltage is initialized over the search space and made to find the peak power. The control block diagram of the IWO scheme is presented in Figure 7. The IWO MPPT coding is deployed in MPPT controller and this controller feeds an output voltage (Vmpp) relevant to maximum possible peak power of the shaded array. The Vmpp is again compared with the actual voltage prevailing in the system and an error is created between these two and processed in PID control to facilitate a relevant duty cycle. The duty cycle is fed to the boost converter to make operate the PV panel at its Vmpp. The operating of boost converter is tuned in accord to the Vmpp in the shaded array. The fitness function of the shaded array is given as

$$
P_{m p p}=i_{1} * V_{1} f\left(i_{1}, G_{1}, T_{1}\right)+i_{2} * V_{2} f\left(i_{2}, G_{2}, T_{2}\right)+i_{3} * V_{3} f\left(i_{3}, G_{3}, T_{3}\right)
$$

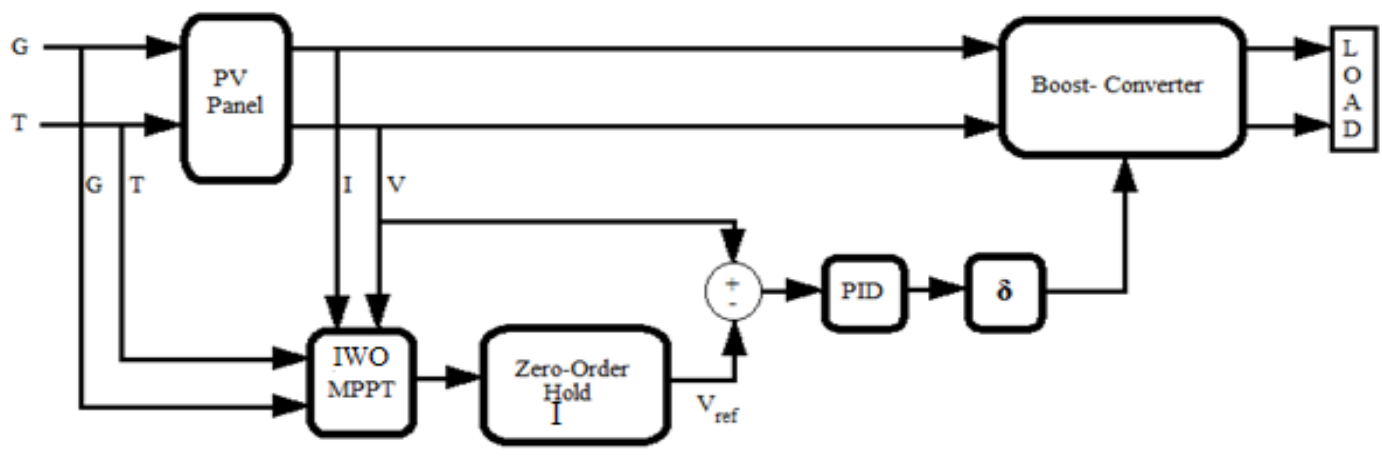

Figure 7. Circuit proposed

\subsection{IWO MPPT Control Approach}

Stage 1: Fix the required parameters for IWO.

Stage 2: Label the batch of weeds (working arbitrary voltage esteems) and scatter them through the hunt space. The inquiry space is kept through the open circuit voltage and short out current of the shaded PV exhibit.

Stage 3: Each batch produce various weeds, equivalent to the underlying populace size, and wellness is computed for each weed. The fitness (Pmax) is assessed for each voltage value and they are sorted to best fitness and worst in each batch refer (4).

Stage 4: Breed number of seeds for each weed in weed bunch utilizing typical dispersion with mean equivalents zero and fluctuating standard deviation as indicated by condition (5) [31].

Stage 5: Add up the new seeds for each weed to its weed set. In a more delineated manner select the new weed for each set to know the most ideal and nearest arrangement.

Stage 6: Guarantee that the new seeds (powers) fulfil the power and voltage limits limitation of the predetermined populace [31].

Stage 7: Apply focused rejection method as cleared up; decide the span of the new populace and check if the size surpassed the most extreme populace at that point revamp the weeds from the best fitted to the slightest and dispose of the weeds and seeds with that gives the most noticeably awful wellness esteems. At the end of the day, best is voltage at GMPP (Global most extreme Power Point) and most noticeably bad is voltage at LMPP (Local greatest power point).

Stage 13: Repeat till criterion is met. 


\section{RESULTS AND ANALYSIS}

This section presents the detailed analysis of results from the conventional, contemporary and proposed MPPT techniques. The partially shaded PV array possessing a conventional MPPT algorithm will get surely stuck in the local power peak. Figure 8 presents the operating voltage and power of the shaded PV array. It is inferred that for a operating voltage of $13.8 \mathrm{~V}$ the peak power tracked is around 34.3 Watts.
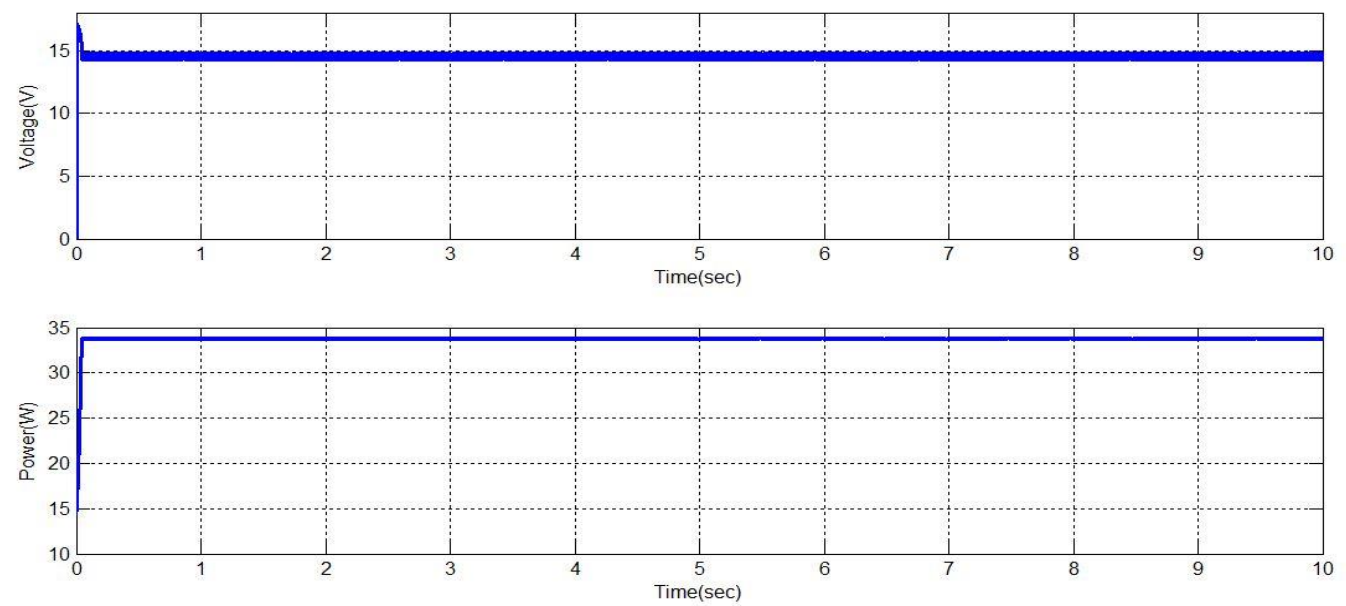

Figure 8. P\& O MPPT voltage and power output for shaded array

The IWO MPPT outputs are shown in Figure 9(a) and (b) and these output waveforms refers to the shaded PV array's operating voltage which gives the respective global power peak. The global power peak extracted through IWO MPPT is presented in 9 (b). The PV shaded array possess two local peaks ( $34.3 \mathrm{~W}$ for $15 \mathrm{Vmpp}$; 43.4 W and 15.06 Vmpp) and one global peak load of 52.1 W.

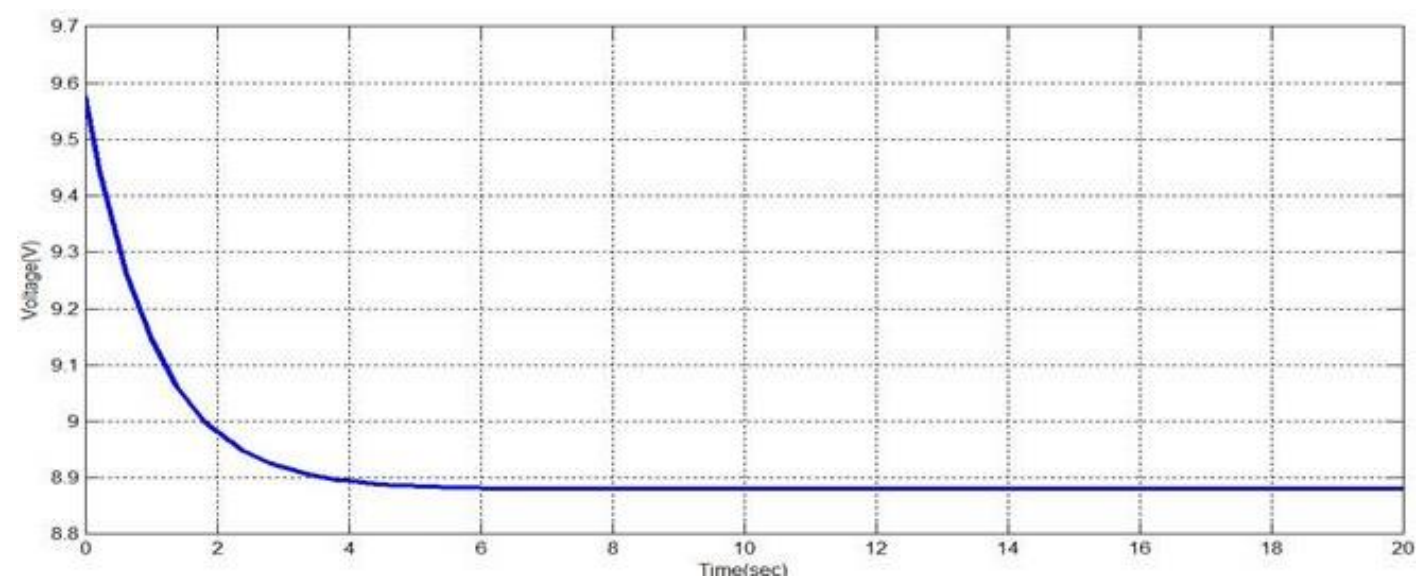

Figure 9(a). Voltage at which IWO MPPT aided peak power extraction

To check the versatility of the IWO MPPT method, various shading patterns are provided. The different shading patterns as tabulated in Table 4. Irrespective of the shading pattern, the IWO controller is so competent to prevail over the conventional techniques. Table 5 presents the comparative results of IWO MPPT with that of other soft computing counterparts like PSO and DE, and it is inferred that the IWO MPPT has a clear edge in terms of convergence and power extracted. 


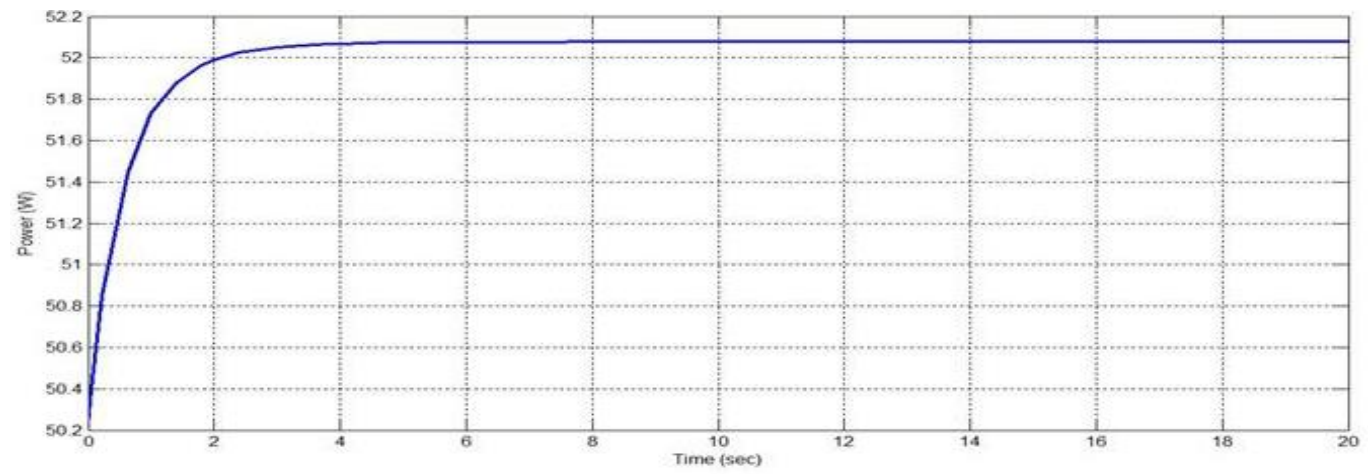

Figure 9(b). IWO MPPT GMPP power

Table 4. Iwo Mppt For Different Shading Pattern

\begin{tabular}{|c|c|c|c|c|c|c|c|c|c|}
\hline & \multicolumn{3}{|c|}{ Shaded condition 1} & \multicolumn{3}{|c|}{ Shaded condition 2} & \multicolumn{3}{|c|}{ Shaded condition 3} \\
\hline & PV 1 & PV 2 & PV 3 & PV 1 & PV 2 & PV 3 & PV 1 & PV 2 & PV 3 \\
\hline Irradiation (sun) & 0.715 & 0.329 & 0.67 & 0.290 & 0.63 & 0.537 & 0.130 & 0.774 & 0.4 \\
\hline Temperature $\left({ }^{\circ} \mathrm{c}\right)$ & 33.05 & 42.47 & 27.90 & 46.04 & 47.25 & 25.81 & 27.20 & 29.25 & 38.02 \\
\hline Operating Voltage (V) & & 15 & & & 14.9 & & & 14.3 & \\
\hline Gmpp (W) & & 58.3 & & & 59.8 & & & 57.8 & \\
\hline
\end{tabular}

Table 5. Comparative Analysis Of Soft Computing Mppt

\begin{tabular}{ccccc}
\hline Tracking Method & Power Extracted (W) & Efficacy $(\%)$ & Convergence & Fluctuation \\
\hline Without MPPT & 14.21 & 18.12 & NA & NA \\
P \& O & (depends on load) & 31.56 & Poor & High \\
PSO & 35.4 & 99.04 & Moderate & Less \\
DE & 51.85 & 98.3 & Moderate & Less \\
IWO & 51.2 & 99.7 & Very Fast & Very Less \\
\hline
\end{tabular}

Figure 10 Show's the comparative responses of soft computing MPPT algorithm for varying irradiation, when the irradiation is changed abruptly the MPPT controller tracks the new MPP point with respect to new irradiation. It is inferred that the proposed IWO MPPT controller prevails over its well entrenched counterparts.

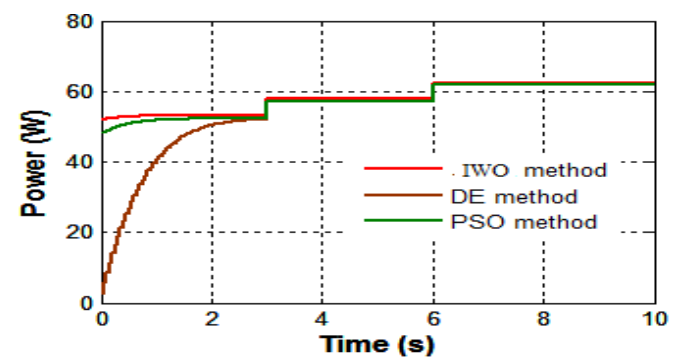

Figure 10. Step change in irradiation and the response of MPPT controllers

\section{CONCLUSION}

Another transformative procedure called IWO has been proposed for MPPT under fractional shading condition. The looking capacity of the proposed IWO calculation is dependable, faster framework to discover GMPP, autonomous and free from the underlying condition and additionally the computational weight is less. The proposed IWO MPPT will prevail in grasping the global power irrespective of the shading pattern of the PV array. The versatility of the suggested technique is tested by dynamically varying the irradiation and temperature and under all conditions it is witnessed that IWO has a clear edge. In all, the proposed strategy (IWO) can track GMPP precisely with great dynamic and in addition enduring state reactions in each sort of natural condition.

An ingenious invasive weed optimization (IWO) aided maximum power tracking for partially... (Sridhar R) 


\section{REFERENCES}

[1] J. M. Carrasco. Power-Electronic Systems for the Grid Integration of Renewable Energy Sources: A Survey. IEEE Transactions on Industrial Electronics, vol. 53, no. 4, pp. 1002-1016, June 2006.

[2] U. Akram, M. Khalid and S. Shafiq. An Innovative Hybrid Wind-Solar and Battery-Super-capacitor Micro grid System-Development and Optimization. IEEE Access, vol. 5, pp. 25897-25912, 2017.

[3] Monadhil Al-Chaderchi1, K. Sopian2, T. Salameh3, D. Zhang4, M. A. Alghoul5. Enhancing the Performance of PV Panel Undergoing Shading Effects. International Journal of Power Electronics and Drive System (IJPEDS), vol. 9, No. 4, December 2018, pp. 1937 1943.

[4] Ali Abdulwahhab Abdulrazzaq, Adnan Hussein Ali. Efficiency Performances of Two MPPT Algorithms for PV System With Different Solar Panels Irradiances.International Journal of Power Electronics and Drive System (IJPEDS), vol. 9, No. 4, December 2018, pp. 1755 1764.

[5] R. John, S. S. Mohammed and R. Zachariah.Variable step size Perturb and observe MPPT algorithm for standalone solar photovoltaic system. 2017 IEEE International Conference on Intelligent Techniques in Control, Optimization and Signal Processing (INCOS), Srivilliputhur, 2017, pp. 1-6.

[6] Shaik Mohammad Irshad, G.P.Ramesh. High Gain Power Generation Based On Hybrid Renewable Energy for AC Load Application. Indonesian Journal of Electrical Engineering and Computer Science (IJEECS), vol. 12, No. 3, December 2018, pp. 1195 1202.

[7] L. Cristaldi, M. Faifer, C. Laurano, R. Ottoboni and S. Toscani. Experimental comparison of MPPT algorithms. 2016 IEEE International Instrumentation and Measurement Technology Conference Proceedings, Taipei, 2016, pp. 1-6.

[8] Z. Mao, Z. Sunan, M. Peng, S. Yanlong and Z. Weiping. Modelling of PV module and its application for partial shading analysis - part I: model and parameter estimation of PV module. The Journal of Engineering, vol. 2017, no. 13, pp. 1295-1298, 2017.

[9] R. Sridhar,S. Jeevananthan,S. S. Dash and Pradeep Vishnur.A new maximum power tracking in PV system during partially shaded conditions based on shuffled frog leap algorithm. Journal of Experimental \& Theoretical Artificial Intelligence, vol 29, 2017 - Issue 3, June 2016.

[10] R. Guruambeth and R. Ramabadran. Fuzzy logic controller for partial shaded photovoltaic array fed modular multilevel converter. IET Power Electronics, vol. 9, no. 8, pp. 1694-1702, June 2016.

[11] Syafaruddin, E. Karatepe and T. Hiyama. Artificial neural network polar coordinated fuzzy controller based maximum power point tracking control under partially shaded conditions, IET Renewable Power Generation, vol. 3, no. 2, pp. 239-253, June 2009.

[12] T. Nahak and Y. Pal. Comparison between conventional, and advance maximum power point tracking techniques for photovoltaic power system. 2016 IEEE 7th Power India International Conference (PIICON), Bikaner, 2016, pp. 1-5.

[13] R. Sridhar,S. Jeevananthan and Pradeep Vishnuram. Particle swarm optimisation maximum power-tracking approach based on irradiation and temperature measurements for a partially shaded photovoltaic system. International Journal of Ambient Energy, Vol- 38, 2017 - Issue 7, May 2016.

[14] M. Miyatake, M. Veerachary, F. Toriumi, N. Fujii and H. Ko. Maximum Power Point Tracking of Multiple Photovoltaic Arrays: A PSO Approach. IEEE Trans. Aerospace and Electronic Systems, vol. 47, no. 1, pp. 367-380, January 2011.

[15] Shubhajit Roy Chowdhury and HiranmaySaha. Maximum power point tracking of partially shaded solar photovoltaic arrays. Solar Energy Materials and Solar Cells, vol. 94, pp. 1441-1447, Jan. 2010.

[16] K. Ishaque, Z. Salam, M. Amjad and S. Mekhilef. An Improved Particle Swarm Optimization (PSO)-Based MPPT for PV With Reduced Steady-State Oscillation. IEEE Trans. Power Electronics, vol. 27, no. 8, pp. 3627-3638, Aug. 2012.

[17] H. Renaudineau. A PSO-Based Global MPPT Technique for Distributed PV Power Generation. IEEE Transactions on Industrial Electronics, vol. 62, no. 2, pp. 1047-1058, Feb. 2015.

[18] C. Manickam, G. R. Raman, G. P. Raman, S. I. Ganesan and C. Nagamani. A Hybrid Algorithm for Tracking of Global MPP based on Perturb and Observe and Particle Swarm Optimization with Reduced Power Oscillation in String Inverters. IEEE Trans. Industrial Electronics, Early Access.

[19] Mohammad Mehdi Seyed mahmoudian, Rasoul Rahmani, Saad Mekhilef, Amanullah Maung Than Oo, Alex Stojcevski, Tey Kok Soon, and Alireza Safdari Ghandhari. Simulation and Hardware Implementation of New Maximum Power Point Tracking Technique for Partially Shaded PV System Using Hybrid DEPSO Method. IEEE Trans. Sustainable Energy, vol. 6, no. 3, pp. 850-862, July 2015.

[20] A. H. Besheer and M. Adly. Ant colony system based PI maximum power point tracking for stand alone photovoltaic system. 2012 IEEE International Conference on Industrial Technology, Athens, pp. 693-698,2012.

[21] M. Sheraz and M. A. Abido. An efficient MPPT controller using differential evolution and neural network. 2012 IEEE International Conference on Power and Energy (PECon), Kota Kinabalu, 2012, pp. 378-383.

[22] Y. Shiqin, J. Jianjun and Y. Guangxing. A Dolphin Partner Optimization. 2009 WRI Global Congress on Intelligent Systems, Xiamen, pp. 124-128,2009.

[23] G Pradhan and P. D. Dewangan. Solving optimal load dispatch problem using enhanced BAT optimization algorithm. 2017 Innovations in Power and Advanced Computing Technologies (i-PACT), Vellore, pp. 1-6, 2017.

[24] Yang X-S. Firefly algorithm, stochastic test functions and design optimization. International journal of BioInspired Computation (IJBIC) vol 2,2010. 
[25] Oftadeh R, Mahjoob MJ, Shariatpanahi M. A novel meta-heuristic optimization algorithm inspired by group hunting of animals: hunting search. Computer and Mathematics Applications, vol 60,pp. 2087-2098,2010.

[26] Z. Jing, G. Yuelin and Y. He. A new hybrid algorithm for modeling of flow shop scheduling: Bird mating optimizer based on GA. 2016 Chinese Control and Decision Conference (CCDC), Yinchuan, pp. 2161-2166, 2016.

[27] Faseela C. K., H. Vennila. Economic and Emission Dispatch using Whale Optimization Algorithm (WOA). International Journal of Electrical and Computer Engineering (IJECE), vol. 8, No. 3, June 2018, pp. 1297 1304.

[28] SeyedaliMirjalili and Andrew Lewis. The Whale Optimization Algorithm. Advances in Engineering Software, vol. 95, pp. 51-67, Jan. 2016.

[29] S. Lin, and B.W. Kernighan. An effective heuristic algorithm for the traveling salesman problem. Oper. Res., vol. 21, pp. 498-498,1973.

[30] A. Dastranj, H. Abiri and A. Mallahzadeh. Design of a Broadband Cosecant Squared Pattern Reflector Antenna Using IWO Algorithm. In IEEE Transactions on Antennas and Propagation, vol. 61, no. 7, pp. 3895-3900, July 2013.

[31] M. M. Nagib, M. M. Othman, A. A. Naiem and Y. G. Hegazy. Integrating tidal energy to solve dynamic economic load dispatch problem using IWO. 2017 IEEE International Conference on Environment and Electrical Engineering and 2017 IEEE Industrial and Commercial Power Systems Europe (EEEIC / I\&CPS Europe), Milan, 2017, pp. 1-6.

[32] Yongquan Zhou, QifangLuo, and Huan Chen. A Novel Differential Evolution Invasive Weed Optimization Algorithm for Solving Nonlinear Equations Systems. Journal of Applied Mathematics, vol. 2013, 2013.

[33] S. Mekni, and B.C. Fayech. A modified invasive weed optimization algorithm for multi objective flexible job shop scheduling problems. International Journal Computer Science and Information Technology, vol. 6, pp.51-60, December 2014. 